\title{
QUALIDADE FISIOLÓGICA DE SEMENTES DE Brachiaria brizantha CV. MARANDU COM VARIAÇÃO NAS CARACTERISTICAS DE PUREZA
}

\author{
Vanessa Taques Batista ${ }^{1}$, Joseli Viviane Ditzel Nunes ${ }^{1}$, Lúcia Helena Pereira Nóbrega ${ }^{1}$ \\ ${ }^{1}$ Universidade Estadual do Oeste do Paraná, E-mail: joselinunes@yahoo.com.br, vanessa.taques@agroplano.net.br, \\ lucia.nobrega@unioeste.br
}

\section{RESUMO}

O objetivo deste estudo foi avaliar a qualidade fisiológica de sementes de Brachiaria brizantha cv. Marandu de dois lotes comerciais com diferentes teores de pureza. As sementes com maior pureza apresentaram melhor qualidade fisiológica, influenciando diretamente no estabelecimento e manutenção de pastagens, sendo as mais indicadas para serem utilizadas pelos produtores rurais, já que as mesmas apresentam maior vigor e, consequentemente, podem apresentar melhores resultados no campo e reduzir o custo de produção.

Palavras-chave: Germinação, Pastagens, Vigor

\section{PHYSIOLOGICAL SEED QUALITY OF Brachiaria brizantha CV. MARANDU WITH DIFFERENT PURITY CHARACTERISTICS}

\begin{abstract}
The objective of this study was to evaluate the physiological quality of Brachiaria brizantha cv. Marandu, in two trading lots with different levels of purity. Seeds with highest purity showed better physiological quality, directly influencing the establishment and maintenance of pastures. Thus, there are the most likely to be used by farmers, since they will have higher vigor and hence can show better results in field and reduce production cost.
\end{abstract}

Keywords: Germination, Pastures, Vigor

\section{INTRODUÇÃO}

A pecuária é um setor importante para o agronegócio brasileiro, tanto no âmbito da produção de carnes como no setor lácteo. O Brasil vem se destacando na produção pecuária, principalmente quanto a controles sanitários e qualidade de carne, sendo possível conquistar novos mercados devido a tais fatores (IBGE, 2012). Ainda é importante acrescentar que o mercado interno tem maior representatividade para o setor, sendo a população brasileira um dos maiores consumidores mundiais de carne bovina, atingindo, pela segunda vez consecutiva, novo recorde histórico na série 
trimestral de abate de bovinos, chegando a 8,913 milhões de cabeças abatidas (IBGE, 2013).

Segundo dados do Departamento de Agricultura dos Estados Unidos (USDA, 2013), o Brasil apresenta o segundo maior rebanho comercial do mundo, cerca de 247,2 milhões de cabeças de gado. Enquanto que em 2012 o rebanho brasileiro era de 211,2 milhões de cabeças de gado, representando cerca de mais de um animal por habitante, distribuído em área produtiva de pastagens de 172 milhões de ha, ou seja, com taxa de ocupação de 1,2 cabeça ha ${ }^{1}$ na produção extensiva (IBGE, 2012).

É possível observar com os dados citados, que a taxa de ocupação é muito baixa, significando que poucos animais engordam em área de um hectare de pastagens. O principal motivo desta baixa produtividade está na qualidade das pastagens brasileiras, as quais apresentam algum grau de deterioração. Os produtores brasileiros escolhem, em sua grande maioria, a produção de gado extensiva, devido principalmente ao baixo custo de produção (SANTOS et al., 2009). Desta forma, não se atentam a investimentos em novas tecnologias e a manutenção dessas pastagens com a utilização de adubação mineral, contribuindo assim, para a degradação e baixa produtividade das pastagens extensivas (GONSALVES \& FRANCHINI, 2007).

Diante do cenário de áreas degradadas, existe incentivo para que essas áreas sejam recuperadas, principalmente por parte de órgãos de extensão e assistência técnica, como também dos setores de captação de recursos financeiros. A reforma de pastagens envolve aquisição de sementes de espécies forrageiras, como Brachiaria brizantha cv. Marandu, para recomposição das áreas. Todavia, as sementes de espécies forrageiras, no Brasil, apresentam amplitude de qualidade que pode contribuir para a otimização das pastagens brasileiras (DIAS \& ALVES, 2008).

As sementes com baixo valor cultural (VC) representam grande parte do mercado de sementes de pastagens, com grandes desvantagens ao produtor, devido o mesmo, no momento da aquisição, comprar não somente as sementes, mas também as impurezas. Essas impurezas, por sua vez, ainda podem dificultar o estabelecimento das pastagens, dificultando a semeadura. A pureza das sementes interfere diretamente no cálculo de (VC) dos lotes de sementes, que é expresso em porcentagem e obtido a partir da multiplicação da porcentagem de sementes puras pela porcentagem de germinação, dividindo-se por 100 
(MARTINS et al., 1998; BRASIL, 2009).

Apesar do baixo VC, essas sementes são as mais adquiridas pelos produtores da atividade pecuária devido a redução de preço no mercado.

A qualidade das sementes de $B$. brizantha está relacionada a diversos fatores, entre os principais: genéticos, fisiológicos e sanitários, interferindo diretamente no vigor das sementes comerciais, qualidade e produtividade (PARIZ et al., 2010). Desta forma, estudos relacionados à qualidade fisiológica dos materiais de B. brizantha $\mathrm{cv}$. Marandu, com variação de pureza, são importantes devido sua representatividade e importância no cenário de produção extensiva de gado de corte.

Neste cenário, objetivou-se com este trabalho comparar a qualidade de sementes comerciais de $B$. brizantha $\mathrm{cv}$. Marandu com variação nas características de pureza.

\section{MATERIAL E MÉTODOS}

As sementes utilizadas nos testes foram adquiridas no comércio, no ano de 2012, originadas de lote deste mesmo ano. Uma das variedades trata-se da SOESP, com as seguintes características: CV 92\%, sementes tratadas com fipronil e recobrimento com grafite. A outra variedade utilizada foi proveniente das Sementes Fortaleza, com CV de $61 \%$ sem tratamento e recobrimento. O acondicionamento das sementes ocorreu em temperatura e umidade ambiente, durante três meses.

Com o objetivo de avaliar o desempenho das sementes no campo, para os testes realizados, as sementes não passaram por seleção de pureza, sendo submetidas aos testes com as porcentagens de $\mathrm{CV}$ que constavam na rotulagem, conforme citado anteriormente.

Para avaliar a qualidade física e fisiológica das sementes, foram determinados grau de umidade, massa de 100 sementes, e realizados testes de germinação, envelhecimento acelerado, teste de frio e tetrazólio, no Laboratório de Avaliação de Sementes e Plantas (LASP) do Centro de Ciências Exatas e Tecnológicas da Universidade Estadual do Oeste do Paraná (UNIOESTE), campus de Cascavel-Paraná.

O grau de umidade foi determinado com quatro subamostras de cada tratamento com cerca de $5 \mathrm{~g}$ cada. As sementes foram dispostas em cápsulas de alumínio e levadas à estufa a $105 \pm 3{ }^{\circ} \mathrm{C}$ por 24 horas. Os resultados foram expressos em porcentagem. $\mathrm{O}$ teste de germinação foi conduzido conforme prescrição da RAS, realizado com quatro repetições de 50 sementes por 
tratamento. As sementes foram submetidas à pré-secagem a $35-40{ }^{\circ} \mathrm{C}$ por sete dias. Após, as sementes foram dispostas em caixas gerbox $(11 \times 11 \times 3,5 \mathrm{~cm})$, sobre uma folha de papel mata- borrão, umedecida com quantidade de água equivalente a 2,5 vezes a massa do substrato seco. A germinação foi realizada em câmaras tipo BOD com temperatura alternada de $15-35^{\circ} \mathrm{C}$, com iluminação durante 8 horas. $\mathrm{O}$ teste foi avaliado, após 21 dias, computando-se a porcentagem de sementes germinadas ao final do teste. A primeira contagem foi realizada aos sete dias após o início do teste padrão de germinação. A determinação da massa de 100 sementes foi realizada com quatro sub amostras de 100 sementes de cada tratamento. Os resultados foram expressos em gramas por 100 sementes (BRASIL, 2009).

Para o teste de envelhecimento acelerado foi utilizada metodologia descrita por Marcos Filho (1999).

As sementes ficaram distribuídas sobre telas de alumínio em caixas gerbox, contendo $40 \mathrm{~mL}$ de água destilada no fundo, de tal forma que se obtenha $100 \%$ de umidade em seu interior. As caixas foram colocadas a $43{ }^{\circ} \mathrm{C}$ por $48 \mathrm{~h}$ em câmaras de envelhecimento. Após este período, as sementes foram colocadas para germinar, conforme descrito no teste de germinação. Os resultados foram expressos em porcentagem (BRASIL, 2009).

Para o teste de frio, Loeffler et al. (1985) preconizaram que as sementes de Brachiaria sejam expostas à temperatura de $10{ }^{\circ} \mathrm{C}$, por sete dias, dispostas em caixas gerbox. Após este período, foram então submetidas ao teste de germinação, conforme descrito anteriormente. Os resultados foram expressos em porcentagem. Para o teste de tetrazólio, quatro repetições de 50 sementes, de cada tratamento, foram pré-umedecidas com água, em papel germiteste, submetidas ao germinador a $20^{\circ} \mathrm{C}$, por 18 horas. Decorrido esse período, as sementes foram cortadas longitudinalmente, com auxílio de bisturi, em até aproximadamente três quartos do comprimento do endosperma. As sementes foram colocadas em copos plásticos de $50 \mathrm{~mL}$ e recobertas com solução de $1,0 \%$ de cloreto 2-3-5 trifenil tetrazólio e mantidas por 18 horas, a $30{ }^{\circ} \mathrm{C}$. As sementes foram avaliadas considerando-se a localização e a intensidade da coloração de suas partes, permitindo identificar duas categorias: sementes vivas e não vivas (BRASIL, 2009). Os resultados foram expressos em porcentagem. 
O delineamento experimental utilizado foi inteiramente casualisado (DIC) com dois tratamentos e quatro repetições para cada tratamento. Os resultados foram submetidos à análise de variância e comparação de médias pelo teste de Tukey a $5 \%$ de probabilidade e processados pelo programa SISVAR (FERREIRA, 2008).

\section{RESULTADOS E DISCUSSÃO}

Houve diferença estatística entre as variedades de Brachiaria brizantha cv. Marandu nos valores médios de massa de 100 sementes e grau de umidade. (Tabela 1).

De acordo com Laura et al. (2009), a massa das sementes pode ser influenciada pelas condições climáticas, região geográfica, época de colheita, nutrição das plantas e pelas características genéticas de cada espécie. Estes autores encontraram valores médios de massa de cem sementes de 3,$82 ; 5,45$; e $8,43 \mathrm{~g}$ respectivamente, para $B$. humidicola, B. decumbens e B. brizantha.

A variedade de Brachiaria com maior teor de pureza (92\%) apresentou 18,18 g. Essa diferença pode ser explicada, pois a variedade SOESP recebeu tratamento de recobrimento com fungicidas e grafite, fazendo com que estas sementes ficassem maiores e com maior massa.

Já Brachiaria de variedade Fortaleza, com pureza de $61 \%$, apresentou menor valor de massa $(3,09 \mathrm{~g})$, sendo este bem menor quando comparado com $B$. brizantha $(8,43 \mathrm{~g})$ com pureza de $63,8 \%$, avaliado por Laura et al. (2009).

Tabela 1. Valores médios de massa de 100 sementes e grau de umidade de sementes de $B$. brizantha cv. Marandu com pureza de 61 (Fortaleza) e 92\% (SOESP), Cascavel 2012.

\begin{tabular}{ccc}
\hline Brachiaria & $\begin{array}{c}\text { Massa de 100 sementes } \\
(\mathbf{g})\end{array}$ & $\begin{array}{c}\text { Grau de umidade } \\
(\%)\end{array}$ \\
\hline Fortaleza & $3,09 \mathrm{~b}$ & $5,1 \mathrm{~b}$ \\
SOESP & $18,18 \mathrm{a}$ & $7,2 \mathrm{a}$ \\
\hline CV (\%) & 3,93 & 6,68 \\
Média geral & 10,63 & 6,15 \\
\hline
\end{tabular}

Médias seguidas pela mesma letra, na coluna, não diferem entre si pelo teste de Tukey a 5\% de probabilidade. Os dados apresentados são os obtidos das observações originais, seguidos das letras obtidas na comparação de médias em transformados em $\sqrt{x}$ 
Esta diferença pode ser expressa devido à diversidade de cultivares de Brachiaria existentes no mercado.

A variedade com maior grau de umidade foi a SOESP (7,2\%), enquanto a variedade Fortaleza apresentou grau de umidade de 5,1\%. Maiores valores de teor de água foram encontrados por Pariz et al. (2010) quando verificaram que as sementes de $B$. brizantha e B. ruziziensis tiveram valores de 11,38 e $11,8 \%$ respectivamente, de grau de umidade. No entanto, quando o grau de umidade é maior, há aumento da massa de 100 sementes, como foi verificado na variedade da SOESP.

Observa-se diferença estatística entre as variedades de Brachiaria para a germinação e viabilidade de sementes, na avaliação aos sete e 21 dias (Tabela 2).

Aos sete dias foi observado que a variedade SOESP apresentou maior porcentagem de germinação $(40 \%)$, e a variedade Fortaleza mostrou baixa germinação (17\%). Aos vinte e um dias, a Brachiaria SOESP apresentou $60 \%$ de porcentagem de germinação e a Brachiaria Fortaleza manteve a mesma porcentagem de germinação dos sete dias.

Pariz et al. (2010) encontraram maiores valores de germinação de sementes de $B$. brizantha tanto na primeira contagem (61\%), como aos 21 dias (79\%). Custódio et al. (2012), também encontraram elevados valores de porcentagem de germinação em cinco lotes de sementes de B. brizantha, variando de 64 a $91 \%$. Os baixos valores de porcentagem de germinação, encontrados neste estudo, podem ser explicados pela restrita quantidade de água contida nas sementes, causando a morte de muitos embriões, ou ainda, no caso específico da Brachiaria Fortaleza, devido à quantidade de sementes chochas, revelada pela pureza interior.

Tabela 2. Porcentagem de germinação e teste de frio de sementes de B. brizantha cv. Marandu com purezas de 61\% (Fortaleza) e 92\% (SOESP), Cascavel - 2012.

\begin{tabular}{|c|c|c|c|}
\hline Brachiaria & Germ & ão (\%) & Tetrazólio (\%) \\
\hline & 7 dias & 21 dias & \\
\hline Fortaleza & $17 \mathrm{~b}$ & $17 \mathrm{a}$ & $36 \mathrm{a}$ \\
\hline SOESP & $40 \mathrm{a}$ & $60 \mathrm{~b}$ & $86 \mathrm{~b}$ \\
\hline CV (\%) & 25,81 & 14,06 & 9,78 \\
\hline Média geral & 37 & 47 & 79 \\
\hline
\end{tabular}


Comparando-se os valores encontrados para germinação e viabilidade determinada pelo teste de tetrazólio, observam-se maiores valores para sementes viáveis. Isso provavelmente ocorreu porque as sementes apresentavam dormência e não conseguiram germinar, permanecendo duras. Porém o tetrazólio consegue indicar as sementes vivas, mesmo que não apresentem germinação no momento do teste, mesmo quanto à viabilidade, foram maiores os valores encontrados para a variedade SOESP, $86 \%$ contra $36 \%$ encontrados para a Fortaleza.

O teste de tetrazólio e germinação podem ser considerados complementares, permitindo assim, em conjunto, avaliar a qualidade fisiológica das sementes (DIAS \& ALVES, 2008). Em estudo com cinco lotes de sementes de B. brizanta cv, Marandu, Custódio et al. (2012) verificaram que a viabilidade das sementes variaram de 81 à 97\%, demonstrando serem estas de alto vigor, bem como a variedade SOESP estudada.

Foram registrados os valores de porcentagem de germinação após submissão ao envelhecimento acelerado e teste de frio das sementes de B. brizantha cv. Marandu com diferentes purezas (Tabela 3).

Segundo Meschede (2004), o teste de envelhecimento acelerado é um método capaz de superar a dormência de sementes de B. brizantha cv. Marandu, isso explica os valores de porcentagem de germinação (Tabela 2) serem menores do que os valores de envelhecimento acelerado (Tabela 3). Resultados divergentes foram encontrados por Pariz et al. (2010), em função das sementes de $B$. brizantha apresentarem baixa dormência e boa germinação (79\%), em condições normais.

Tabela 3. Resultados de envelhecimento acelerado e teste de frio em sementes de $B$. brizantha cv. Marandu com purezas de 61\% (Fortaleza) e 92\% (SOESP), Cascavel - 2012.

\begin{tabular}{lcccc}
\hline Brachiaria & \multicolumn{2}{c}{ Envelhecimento (\%) } & \multicolumn{2}{c}{ Frio (\%) } \\
& 7 dias & 21 dias & 7dias & 21 dias \\
\hline Fortaleza & $20 \mathrm{~b}$ & $23 \mathrm{~b}$ & $8 \mathrm{~b}$ & $12 \mathrm{~b}$ \\
SOESP & $64 \mathrm{a}$ & $66 \mathrm{a}$ & $44 \mathrm{a}$ & $59 \mathrm{a}$ \\
\hline CV $(\%)$ & 23,20 & 20,13 & 25,30 & 20,52 \\
Média geral & 52 & 56 & 48 & 41,5 \\
\hline Médias seguidas pela mesma letra, na coluna, não diferem entre si pelo teste de Tukey a 5\% de probabilidade. Os dados \\
apresentados são os obtidos das observações originais, seguidos das letras obtidas na comparação de médias transformados em \\
$\operatorname{arcsen} \sqrt{\frac{x}{100}}$.
\end{tabular}


Quanto ao teste de frio, nas duas épocas de avaliação, tanto na primeira contagem que foi realizada ao $7^{\circ}$ dia como aos 21 dias, a variedade SOESP apresentou maior porcentagem de germinação do que a Fortaleza, com valores de 44 e 59\%, respectivamente. A variedade Fortaleza apresentou baixos valores de porcentagem de germinação, sendo de $8 \%$ na primeira contagem e $12 \%$ aos 21 dias. O teste de frio em sementes é utilizado para verificar o vigor, portanto as sementes de variedade Fortaleza, a partir deste teste, podem ser consideradas pouco vigorosas.

$\mathrm{O}$ estresse térmico provocado pelo teste frio afetou negativamente a germinação das sementes da variedade Fortaleza e não afetou a germinação da variedade SOESP.

Sem dúvida, as sementes da variedade SOESP apresentaram melhor qualidade, porém não se pode desconsiderar a proteção que o recobrimento traz às sementes. Isso pode ser verificado destacadamente nos resultados apresentados no teste de frio. As sementes da variedade Fortaleza apresentaram queda de qualidade, sendo altamente sensíveis à baixa temperatura acarretada pelo teste. Já as sementes da variedade SOESP mantiveram a qualidade, levando a crer que o recobrimento protege a semente das amplitudes térmicas e as mantêm vigorosas.

\section{CONCLUSÕES}

As sementes com maior pureza (SOESP) apresentam melhor qualidade fisiológica o que influencia diretamente no estabelecimento e manutenção de pastagens. Desta forma, as sementes com maior porcentagem de pureza são as mais indicadas para serem adquiridas pelos produtores rurais, já que têm maior vigor e, consequentemente, podem apresentar melhores resultados no campo. Porém, devido ao alto valor de mercado, a grande maioria dos pecuaristas ainda tem preferência pelas sementes com menor pureza, refletindo a baixa tecnologia utilizada pelo setor de pastagens.

\section{REFERÊNCIAS}

BRASIL. 2009. Ministério da Agricultura. Regras para análise de sementes. Brasília: Secretaria Nacional de Defesa Agropecuária, 395 p. Disponível em: $<$ http://www.agricultura.gov.br/arq_editor/fil e/2946_regras_analise_sementes.pdf $>$

Acesso em: Dēz. de 2012.

CUSTÓDIO, C. C.; DAMASCENO, R. L.; MACHADO NETO, N. B. 2012. Imagens digitalizadas na interpretação do teste de tetrazólio em sementes de Brachiaria brizantha. Revista Brasileira de Sementes, Londrina, v.34, n.2, p. 334-341. 
DIAS, M. C. L. L; ALVES, S. J. 2008. Avaliação da viabilidade de sementes de Brachiaria brizantha pelo teste de tetrazólio. Revista Brasileira de Sementes, Pelotas, v.30, n.3, p.145-151.

FERREIRA, D. F. 2008. SISVAR: um programa para análises e ensino de estatística. Revista Científica Symposium, Lavras, v.6, n.2, p.36-41.

GONÇALVES, L. S.; FRANCHINI, C. J. 2007. Integração lavoura pecuária. Londrina, Paraná: EMBRAPA, 8p. (Circular Técnica, 44).

IBGE: Censo agropecuário. 2012. Disponível em: $<$ http://www.ibge.gov.br/home/estatistica/ec onomia/ppm/2010/default_pdf.sht>. Acesso em: Nov. de 2012.

IBGE: Censo agropecuário. 2014. Disponível em: $<$ http://www.beefpoint.com.br/cadeia-produt iva/giro-do-boi/abate-de-bovinos-atinge-reco rde-no-3o-trimestre-de-2013-ibge/>. Acesso em: Fev. de 2014.

LAURA, V. A.; RODRIGUES, A. P. D'A. C. ARIAS, E. R. A., CHERMOUTHT, K. S., ROSSI, T. 2009. Qualidade física e fisiológica de sementes de braquiárias comercializadas em Campo Grande-MS. Ciencia e Agrotecnologia, Lavras, v. 33 n. 1, p. 326-332.

LOEFFLER, N. L.; MEIER, J. L.; BURRIS, J. S. 1985. Comparison of two cold test procedures for use in maize drying studies. Seed Science and Technology, Zurich, v. 13 , n. 3, p. 653-658.

MARCOS FILHO, J. Testes de vigor: importância e utilização. In: KRZYZANOWSKI, F. C.; VIEIRA, R. D.; FRANÇA NETO, J. B. 1999. (Ed.). Vigor de sementes: conceitos e testes. Londrina: ABRATES, cap.1, p.1-21.
MARTINS, L.; LAGO, A. A.; GROTH, D. 1998. Valor cultural de sementes de Brachiaria brizantha (Hochst.ex A.Rich) Stapf durante o armazenamento. Revista Brasileira de Sementes, Londrina, v. 20, n. 1, p. 60-64.

MESCHEDE, D. K.; SALES, C. G. J.; BRACCINI, L. A.; SCAPIM, A. C.; SCHUAB, R. S. 2004. Tratamento para superação de dormência das sementes de capim-braquiária cultivar Marandu. Revista Brasileira de Sementes, Pelotas, v. 26, n. 2, p. 76-81.

PARIZ, M. C. , FERREIRA, R. L., SÁ, M. E., ANDREOTTI, M., CHIODEROLI, C. A., RIBEIRO, A. P. 2010. Qualidade fisiológica de sementes de Brachiaria e avaliação da produtividade de massa seca em diferentes sistemas de integração lavoura pecuária sob irrigação. Pesquisa Agropecuária Brasileira, Brasília, v. 40, n. 3, p. 330-340.

SANTOS, M. E. R.; FONSECA, M. D.; EUCLIDES, B. P. V.; RIBEIRO, I. J.; NASCIMENTO, D.; MOREIRA, M. L. 2009. Produção de bovinos em pastagens de capim-braquiária diferidas. Revista Brasileira de Zootecnia, Viçosa, v. 38, n. 4, p. 635-642.

USDA. (United States Department of Agriculture) National Nutrient Database for Standard Reference. 2015. Relatórios da agência. Disponível em: $<$ http://www.usda.gov/wps/portal/usda/usda home>Acesso em: Fev. de 2015.

Recebido em: 6/5/2015 Aceito para publicação em: 28/3/2016 